\title{
Serum IgA/C3 ratio and glomerular C3 staining predict progression of IgA nephropathy in children
}

\author{
Yuanyuan Lang', Shaona Song ${ }^{2}$, Linsheng Zhao ${ }^{3}$, Yi Yang ${ }^{1}$, Tao Liu ${ }^{4}$, Yongming Shen ${ }^{1}$, Wenhong Wang ${ }^{2}$ \\ ${ }^{1}$ Department of Clinical Laboratory, Tianjin Children's Hospital, Tianjin, China; ${ }^{2}$ Department of Nephrology, Tianjin Children's Hospital, Tianjin, \\ China; ${ }^{3}$ Department of Pathology, Tianjin Children's Hospital, Tianjin, China; ${ }^{4}$ NHC Key Laboratory of Critical Care Medicine, Tianjin First \\ Central Hospital, Tianjin, China \\ Contributions: (I) Conception and design: Y Lang, S Song, W Wang; (II) Administrative support: W Wang, Y Shen; (III) Provision of study materials \\ or patients: Y Lang, S Song, L Zhao; (IV) Collection and assembly of data: Y Lang, S Song, Y Yang, T Liu; (V) Data analysis and interpretation: Y \\ Lang, Y Yang; (VI) Manuscript writing: All authors; (VII) Final approval of manuscript: All authors. \\ Correspondence to: Yongming Shen. Department of Clinical Laboratory, Tianjin Children’s Hospital, Tianjin, China. Email: Shenymtj@sina.com; \\ Wenhong Wang. Department of Nephrology, Tianjin Children’s Hospital, Tianjin, China. Email: docwwh@163.com.
}

Background: This retrospective study aimed to evaluate the significance of serum immunoglobulin A/ complement 3 (IgA/C3) ratio and glomerular C3 staining at the onset of disease for predicting progression of IgA nephropathy in children.

Methods: A total of 41 children with IgA nephropathy were allocated to two groups according to proteinuria (proteinuria $<50 \mathrm{mg} / \mathrm{kg} /$ day group and proteinuria $\geq 50 \mathrm{mg} / \mathrm{kg} /$ day group) to compare their clinical data. Receiver operating characteristic (ROC) curves were used to evaluate the optimal cutoff value of serum IgA/C3 ratio in two groups. According to the optimal cutoff value of serum $\mathrm{IgA} / \mathrm{C} 3$ ratio and glomerular C3 staining, the children were divided into four groups: Group A (serum IgA/C3 ratio $<2.025$ and glomerular C3 staining <2.0); Group B (serum IgA/C3 ratio $\geq 2.025$ and glomerular C3 staining <2.0); Group $\mathrm{C}$ (serum IgA/C3 ratio <2.025 and glomerular C3 staining $\geq 2.0$ ); and Group D (serum IgA/C3 ratio $\geq 2.025$ and glomerular $\mathrm{C} 3$ staining $\geq 2.0$ ). Then, the risk factors [including proteinuria and glomerular filtration rate (GFR) and pathological findings] were compared in these 4 groups at onset of IgA nephropathy.

Results: Serum IgA/C3 ratio in the proteinuria $<50 \mathrm{mg} / \mathrm{kg} /$ day group was significantly higher compared to the proteinuria $\geq 50 \mathrm{mg} / \mathrm{kg} /$ day group $(\mathrm{P}<0.01)$. According to ROC curves, the optimal cutoff value for the $\mathrm{IgA} / \mathrm{C} 3$ ratio was 2.025 in two groups. At onset of IgA nephropathy, patients with IgA/C3 ratio $<2.025$ were predicted with nephrotic range proteinuria. When glomerular C3 staining was at the same level (glomerular C3 staining <2.0), GFR was significantly lower in group B (serum IgA/C3 ratio 22.025) compared with group A (serum IgA/C3 ratio <2.025). When serum IgA/C3 ratio was at the same level (serum IgA/C3 ratio $<2.025$ ), GFR was significantly lower in group C (glomerular C3 staining $\geq 2.0$ ) compared with group A (glomerular C3 staining <2.0). Pathological findings and MEST (Oxford classification of IgA nephropathy) scores did not differ among the 4 groups at onset of the disease.

Conclusions: Serum IgA/C3 ratio and glomerular C3 staining may be useful markers of the progression of IgA nephropathy in children, but not good markers for pathological findings at the onset of disease.

Keywords: Serum IgA/C3 ratio; glomerular C3 staining; proteinuria; glomerular filtration rate (GFR); IgA nephropathy; children

Submitted Jan 31, 2021. Accepted for publication Mar 17, 2021.

doi: $10.21037 / \mathrm{tp}-21-90$

View this article at: http://dx.doi.org/10.21037/tp-21-90 


\section{Introduction}

Immunoglobulin A Nephropathy (IgAN), defined by the mesangial deposits of $\operatorname{IgA}$ as the predominant immunoglobulin class, is a common glomerular disease identifiable by pathologists and is observed in both children and adults. Most IgAN patients are progressive cases, with $25 \%$ of cases reaching end-stage renal disease (ESRD) in 20 years after diagnosis. The origin of several progressive IgAN varieties often begins in the pediatric age and early intervention could prevent progression of the disease (1). Thus, biomarkers related to IgAN at onset of the disease are needed to predict progression in children.

In 2000, Tomino et al. reported that patients who had higher serum IgA/C3 ratio were more likely to be diagnosed with IgAN (2). Since then, the IgA/C3 ratio has used as a prognostic biomarker not only to evaluate the differential diagnosis between IgAN and other glomerulonephritides, but also to predict progression in IgAN (3-5). Complements activation also plays a very important role in the pathogenesis of IgAN (6). Glomerular C3 staining was found to associate with the severity of pathological findings and could predict prognosis in severe $\operatorname{IgAN}(3,7)$. In this study, we focused on these two biomarkers.

Proteinuria, reduced glomerular filtration rate (GFR), and severe histological lesions were considered as risk factors of nephropathy progression (8). These risk factors, which have been assessed in several clinical studies at onset of the disease, were found to be significantly associated with progression in IgAN $(8,9)$. Thus, in this study, we aimed to evaluate the relationship between biomarkers (serum IgA/C3 ratio and glomerular $\mathrm{C} 3$ staining) and risk factors at the onset of disease for predicting progression of IgA nephropathy in children. We present the following article in accordance with the STARD reporting checklist (available at http://dx.doi.org/10.21037/tp-21-90).

\section{Methods}

This was a retrospective study that included 41 children ( 26 boys and 15 girls) who had been diagnosed with IgA nephropathy in Tianjin Children's Hospital in China from April 2017 to July 2020. Admission criteria were as follows: (I) diagnosis of IgAN according to renal biopsy which showed the presence of IgA deposits predominating over other types of deposits; (II) children with systemic diseases, such as systemic lupus erythematosus or HenochSchoenlein purpura nephritis, were excluded from the study; (III) no previous treatment with immunosuppressive drugs or corticosteroids before.

For this study, we analyzed clinical data, including age, selected biochemical parameters, and renal biopsy findings at the onset of IgAN. We evaluated serum IgA, C3, creatinine, albumin, proteinuria, erythrocyturia, GFR, and calculated the IgA/C3 ratio. Serum IgA and C3 were measured using the immunoturbidimetry method. Proteinuria was measured in a $24-\mathrm{h}$ urine test and was expressed in $\mathrm{mg} / \mathrm{kg} / \mathrm{day}$. Nephrotic range proteinuria was defined as urinary protein $\geq 50 \mathrm{mg} / \mathrm{kg} /$ day and nonnephrotic-range proteinuria was defined as urinary protein $<50 \mathrm{mg} / \mathrm{kg} /$ day. Hematuria included microscopic hematuria which was established as $>5$ erythrocytes per field of view under a microscope, and gross hematuria which was defined as the macroscopic presence of blood in urine. The GFR was calculated based on the Schwartz formula.

The Oxford classification (OC) of IgAN was used to assess IgAN severity according to renal biopsy. The presence of a given finding, including mesangial hypercellularity $(M)$, endocapillary hypercellularity (E), segmental sclerosis (S), and tubular atrophy/interstitial fibrosis $(\mathrm{T})$, was scored 1 . The absence of a given finding was scored 0 . The MEST score $(\mathrm{M}+\mathrm{E}+\mathrm{S}+\mathrm{T})$ ranged from $0-4$. In the biopsy samples, the presence of crescent was also evaluated. In this study, renal biopsies were evaluated by pathologists in the Tianjin Children's Hospital.

The study was conducted in accordance with the Declaration of Helsinki(as revised in 2013). The study was approved by institutional ethics committee of Tianjin Children's Hospital and informed consent was taken from all the patients.

\section{Statistics}

Shapiro-Wilks tests were used to evaluate normal distribution of variables. For normally distributed variables, the Student $t$-test was used to compare differences between mean values in two groups for unpaired samples and analysis of variance (ANOVA) was used in 3 or more groups. For nonnormally distributed variables, the KruskalWallis test was used. The receiver operating characteristic (ROC) curve was used to determine the optimal cutoff value of the $\mathrm{IgA} / \mathrm{C} 3$ ratio for two groups. A P value $<0.05$ was considered statistically significant. The software SPSS version 26.0 (IBM Corp., Armonk, NY, USA) was used for statistical analyses. 
Table 1 Patient baseline characteristics

\begin{tabular}{|c|c|c|c|c|}
\hline Parameter & Overall & $\begin{array}{c}\text { Proteinuria } \\
<50(\mathrm{mg} / \mathrm{kg} / \text { day })\end{array}$ & $\begin{array}{c}\text { Proteinuria } \\
\geq 50(\mathrm{mg} / \mathrm{kg} / \text { day })\end{array}$ & $P$ value \\
\hline Age (years) & $9.37 \pm 2.84$ & $9.85 \pm 2.81$ & $8.9 \pm 2.84$ & NS \\
\hline $\mathrm{M} / \mathrm{F}$ & $26 / 15$ & $13 / 7$ & $13 / 8$ & NS \\
\hline $\lg A(g / L)$ & $2.36 \pm 0.88$ & $2.75 \pm 0.81$ & $1.99 \pm 0.8$ & $<0.01$ \\
\hline Albumin (g/L) & $34.75 \pm 9.14$ & $42.77 \pm 3.34$ & $27.11 \pm 5.56$ & $<0.001$ \\
\hline Creatinine (mg/L) & $56.05 \pm 20.94$ & $55.25 \pm 21.65$ & $56.81 \pm 20.75$ & NS \\
\hline GFR $\left(\mathrm{mL} / \mathrm{min} / 1.73 \mathrm{~m}^{2}\right)$ & $116.87 \pm 41.29$ & $119.01 \pm 46.95$ & $114.83 \pm 36.14$ & NS \\
\hline
\end{tabular}

NS, not significant; GFR, glomerular filtration; C3, complement 3; IgA, immunoglobulin A.

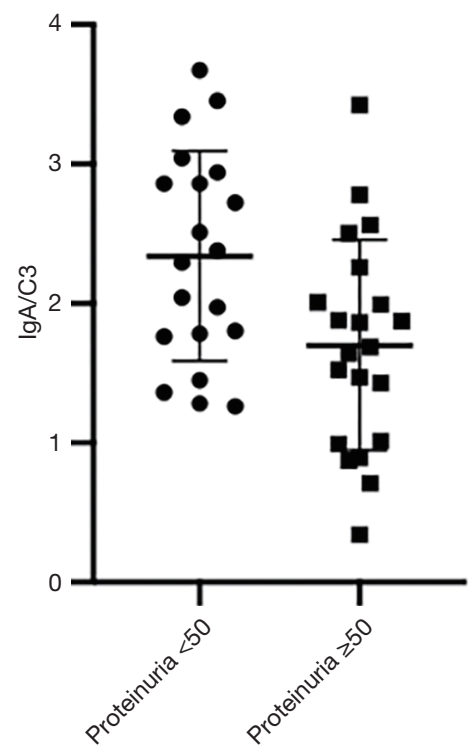

Figure 1 Comparison of serum $\mathrm{IgA} / \mathrm{C} 3$ ratio among two groups. $\mathrm{P}<0$.01. IgA, immunoglobulin A; C3, complement 3 .

\section{Results}

\section{Comparison of patient baseline characteristics among} proteinuria $<50$ (mg/kg/day) group and proteinuria $\geq 50(\mathrm{mg} / \mathrm{kg} /$ day $)$ group

The basic characteristics of 41 children with IgA nephropathy are shown in Table 1 . The average age of the subjects was $9.37 \pm 2.84$ years old. The ratio (male/female) was 1.73:1. Among 41 children with IgA nephropathy, 21 cases had proteinuria (51.22\%), 39 cases had hematuria (including microscopic hematuria and gross hematuria), and the incidence of hematuria was $95 \%$. An elevated serum IgA level was found in 18 participants (41\%).

According to proteinuria levels, participants were divided into two groups: proteinuria $\geq 50 \mathrm{mg} / \mathrm{kg} /$ day group and proteinuria $<50 \mathrm{mg} / \mathrm{kg} /$ day group. We compared the levels of gender, age, IgA, C3, serum $\mathrm{IgA} / \mathrm{C} 3$ ratio, albumin, creatinine, GFR, and hematuria between the two groups. According to Table 1, IgA and IgA/C3 showed statistical differences in the comparison of the two groups. The levels of IgA and IgA/C3 in the proteinuria $<50 \mathrm{mg} / \mathrm{kg} /$ day group were significantly higher than those in the proteinuria $\geq 50 \mathrm{mg} / \mathrm{kg} /$ day group. Gender, age, C3, creatinine, GFR, and hematuria showed no difference between the two groups.

\section{Comparison of serum IgA/C3 ratio among the proteinuria $\geq 50$ (mg/kg/day) group and proteinuria $<50$ (mg/kg/day) groups}

The mean serum IgA/C3 ratio of the proteinuria $\geq 50(\mathrm{mg} / \mathrm{kg} / \mathrm{day})$ group were $1.70 \pm 0.75$, which were significantly lower than those of the proteinuria $<50(\mathrm{mg} / \mathrm{kg} /$ day $)$ group $(2.34 \pm 0.75, \mathrm{P}<0.01$, Figure 1$)$.

Proteinuria can reflect the progression of IgAN. In order to distinguish different proteinuria levels, the ROC curve was used to determine the optimal cutoff value of the IgA/C3 ratio for two groups. The areas under the receiver operating characteristic curves (AUROCs) of the IgA/C3 ratio was as high as 0.717 (sensitivity $60 \%$, specificity $76.2 \%, \mathrm{P}<0.01$; Figure 2 and Table 2). The optimal cutoff value for the $\mathrm{IgA} / \mathrm{C} 3$ ratio was 2.025 . It 
showed that patients with serum IgA/C3 ratio $<2.025$ at onset of the disease could be predicted with nephrotic range proteinuria.

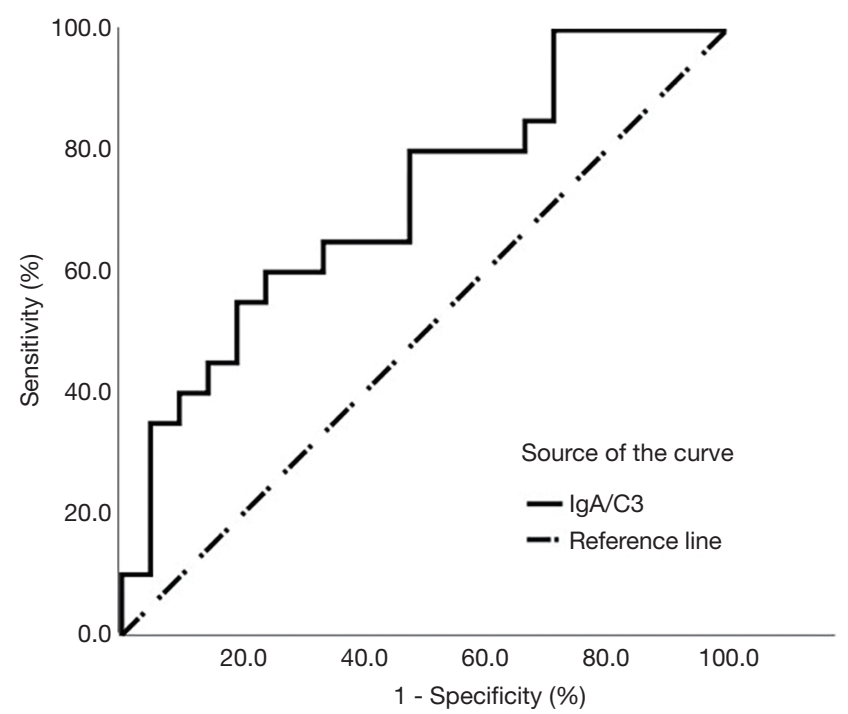

Figure 2 ROC curve for serum $\mathrm{IgA} / \mathrm{C} 3$ ratio in proteinuria $\geq 50$ ( $\mathrm{mg} / \mathrm{kg} /$ day) group and proteinuria $<50$ ( $\mathrm{mg} / \mathrm{kg} /$ day) group. ROC, receiver operating characteristic; IgA, immunoglobulin A; C3, complement 3 .
The children were retrospectively divided into two groups (serum IgA/C3 ratio <2.025 group and serum IgA/C3 ratio $\geq 2.025$ group) based on the optimal cutoff value of serum IgA/C 3 ratio

According to the optimal cutoff value of 2.025, serum $\mathrm{IgA} / \mathrm{C} 3$ ratios were used to allocate patients to the two groups (Table 3). Proteinuria was significantly higher in IgA/C3 $<2.025$ group, compared with IgA/C $3 \geq 2.025$ group. However, GFR did not differ between the two groups.

\section{The children were then divided into four groups based on the optimal cutoff value of serum IgA/C 3 ratio and glomerular C3 staining}

We introduced glomerular C3 staining in our study to further analyze the relationship between the risk factors GFR and serum IgA/C3 ratio. As shown in Table 4, the children were retrospectively divided into four groups according to the optimal cutoff value of serum IgA/C3 ratio and glomerular C3 staining. Group A consisted of 17 children with serum IgA/C3 ratio $<2.025$ and glomerular C3 staining <2.0; Group B consisted of 12 children with serum IgA/C3 ratio $\geq 2.025$ and glomerular C3 staining $<2.0$; Group $\mathrm{C}$ consisted of 7 children with serum IgA/C3

Table 2 Optimal cutoff value of serum IgA/C3 ratio in children with $\mathrm{IgAN}$ for proteinuria $\geq 50$ (mg/kg/day) group and proteinuria $<50$ (mg/kg/day) group

\begin{tabular}{lccccc}
\hline & Cutoff & Sensitivity & Specificity & AUC & P value \\
\hline $\lg / \mathrm{C} 3$ & 2.025 & 0.6 & 0.762 & 0.717 & $<0.01$ \\
\hline
\end{tabular}

AUC, area under the curve; IgA, immunoglobulin A; C3, complement 3.

Table 3 Comparison of laboratory data among two groups

\begin{tabular}{lccc}
\hline Parameter & $\operatorname{lgA} / \mathrm{C} 3<2.025$ & $\operatorname{lgA} / \mathrm{C} 3 \geq 2.025$ & $\mathrm{P}$ value \\
\hline Proteinuria $(\mathrm{mg} / \mathrm{kg} / \mathrm{day})$ & $78.46 \pm 60.67$ & $43.75 \pm 61.73$ & $<0.05$ \\
GFR $\left(\mathrm{mL} / \mathrm{min} / 1.73 \mathrm{~m}^{2}\right)$ & $124.90 \pm 31.26$ & $105.54 \pm 51.23$ & $\mathrm{NS}$ \\
\hline
\end{tabular}

IgA, immunoglobulin A; C3, complement 3; GFR, glomerular filtration rate.

Table 4 Comparison of laboratory data among four groups

\begin{tabular}{lcccc}
\hline Parameter & Group A & Group B & Group C & Group D \\
\hline Proteinuria $(\mathrm{mg} / \mathrm{kg} /$ day $)$ & $88.52 \pm 62.28^{*}$ & $50.58 \pm 71.6$ & $54.02 \pm 32.49$ & $27.36 \pm 25.9^{\star}$ \\
GFR $\left(\mathrm{mL} / \mathrm{min} / 1.73 \mathrm{~m}^{2}\right)$ & $132.96 \pm 29.1^{*}$ & $97.29 \pm 50.32^{*}$ & $105.31 \pm 29.23^{*}$ & $125.34 \pm 53.28$ \\
\hline
\end{tabular}

${ }^{*}, \mathrm{P}<0.05$. GFR, glomerular filtration rate. 
Table 5 Comparison of the pathological finding among four groups

\begin{tabular}{lcccc}
\hline Parameter & Group A & Group B & Group C & Group D \\
\hline M0/M1 & $1 / 16$ & $0 / 12$ & $0 / 7$ & $0 / 5$ \\
E0/E1 & $11 / 6$ & $8 / 4$ & $4 / 3$ & $4 / 1$ \\
S0/S1 & $1 / 16$ & $3 / 9$ & $0 / 7$ & $0 / 5$ \\
T0/T1/T2 & $14 / 2 / 1$ & $7 / 5 / 0$ & $7 / 0 / 0$ & $5 / 0 / 0$ \\
C (absent/present) & $4 / 13$ & $6 / 6$ & $4 / 3$ & $3 / 2$ \\
MEST scores & $2.65 \pm 1.06$ & $2.42 \pm 1.16$ & $2.43 \pm 0.53$ & $2.2 \pm 0.45$ \\
\hline
\end{tabular}

ratio $<2.025$ and glomerular C3 staining $\geq 2.0$; and Group D consisted of 5 children with serum IgA/C 3 ratio $\geq 2.025$ and glomerular C3 staining $\geq 2.0$.

When glomerular C3 staining was at the same level (glomerular C3 staining <2.0), GFR was significantly lower in group B compared with group A. When serum IgA/C3 ratio was at the same level (serum IgA/C3 ratio $<2.025$ ), GFR was significantly lower in group C compared with group A.

Histological analyses are shown in Table 5 according to the Oxford classification criteria. The ratios of $\mathrm{M} 0 / \mathrm{M} 1$, $\mathrm{E} 0 / \mathrm{E} 1, \mathrm{~S} 0 / \mathrm{S} 1, \mathrm{~T} 0 / \mathrm{T} 1 / \mathrm{T} 2$ and the ratios of the absent/ present crescents were all similar in each group. In addition, MEST scores did not differ among the four groups. The combination of serum IgA/C3 ratio (cutoff value 2.025) and glomerular C3 staining is not a good marker for predicting histological severity of kidney lesions at onset of the disease.

\section{Discussion}

Among the forms of glomerular disease, IgAN is the most common worldwide, and is associated with a poor prognosis. In 2011, Suzuki et al. hypothesized that the pathogenesis of IgAN was based on 4 hits. The onset of IgAN required GdIgA1 (Hit 1). With the progression of the disease, endogenous anti-glycan antibodies (Hit 2), subsequent immune complexes formation (Hit 3), and glomerular deposition (Hit 4), were involved in the IgAN pathogenesis (10). IgA-based activation of the complement system also plays a critical role in the pathogenesis of IgAN (11).

Since IgA and C3 mesangial co-deposition is present at immunofluorescence in more than $90 \%$ of patients, serum IgA and $\mathrm{C} 3$ are involved as participants in the pathogenesis of $\operatorname{IgAN}(12,13)$. In Japan, serum IgA was found elevated in $50-70 \%$ of adult patients, and in $16 \%$ of pediatric patients (14). In the study by Mizerska-Wasiak et al., serum
IgA level was found elevated in $52 \%$ of Polish pediatric patients (15). Elevated serum IgA level was found in $22.2 \%$ of Chinese adult patients (16). In our study, $41 \%$ of Chinese pediatric patients had an elevated serum IgA level. Variability regarding the clinical course of patients with IgAN is related to multiple factors, including differences in clinical patterns, age, and geographic prevalence $(10,17)$.

Hematuria is the predominant manifestation of IgAN. In our study, hematuria was present in $95 \%$ of pediatric patients, compared to $92 \%$ in Polish children, and $88 \%$ in Japanese children $(14,15)$.

Clinically, therapy for IgAN depends mostly on risk factors (proteinuria, GFR, and the histopathological findings in renal biopsy) (18). Predictors of poor outcomes in childhood IgAN include proteinuria at the onset of disease. In our study, there were significant differences in mean IgA/C3 ratio between the nephrotic range proteinuria group and the non-nephrotic-range proteinuria group. Serum IgA/C3 ratio was significantly higher in the nonnephrotic-range proteinuria group compared to the nephrotic range proteinuria group, which is consistent with the results reported by Mizerska-Wasiak et al. (15) Serum $\mathrm{IgA} / \mathrm{C} 3$ ratio at onset of the disease could be a predictor in the progression of IgAN.

To further analyze the other risk factors, we introduced glomerular C3 staining in our study. The results showed that when glomerular C3 staining was at the same level (glomerular C3 staining <2.0), GFR was significantly lower in group $\mathrm{B}$ (serum $\mathrm{IgA} / \mathrm{C} 3$ ratio $\geq 2.025$ ) compared with group A (serum IgA/C3 ratio $<2.025$ ), and when serum $\mathrm{IgA} / \mathrm{C} 3$ ratio was at the same level (serum $\mathrm{IgA} / \mathrm{C} 3$ ratio $<2.025$ ), GFR was significantly lower in group C (glomerular C3 staining $\geq 2.0$ ) compared with group A (glomerular C3 staining <2.0). These results confirmed that mesangial C3 deposition was associated with the progression of IgAN (19-22). Because of the relationship between risk factors 
(including proteinuria and GFR) and these biomarkers, we concluded that serum $\mathrm{IgA} / \mathrm{C} 3$ ratio and glomerular $\mathrm{C} 3$ staining at onset of IgAN could predict the progression of IgA nephropathy in children.

After rating renal biopsy findings using the Oxford classification, we found that there was no relationship between M0/M1, E0/E1, S0/S1, T0/T1/T2, absence/ presence of crescents as well as MEST scores, and these two biomarkers at the first renal biopsy. A study by Stefan also showed that there was no correlation between IgA/C3 ratio and the Oxford classification in European adult patients (23).

This study was relatively small in scale, and the findings require confirmation via a large scale study. However, we believed it was worthy to conclude that serum $\mathrm{IgA} / \mathrm{C} 3$ ratio and glomerular C3 staining may be useful biomarkers of the progression of IgA nephropathy in children.

\section{Acknowledgments}

Funding: None.

\section{Footnote}

Reporting Checklist: The authors have completed the STARD reporting checklist. Available at http://dx.doi.org/10.21037/ tp-21-90

Data Sharing Statement: Available at http://dx.doi. org/10.21037/tp-21-90

Conflicts of Interest: All authors have completed the ICMJE uniform disclosure form (available at http://dx.doi. org/10.21037/tp-21-90). The authors have no conflicts of interest to declare.

Ethical Statement: The authors are accountable for all aspects of the work in ensuring that questions related to the accuracy or integrity of any part of the work are appropriately investigated and resolved. The study was conducted in accordance with the Declaration of Helsinki (as revised in 2013). The study was approved by institutional ethics committee of Tianjin Children's Hospital and informed consent was taken from all the patients.

Open Access Statement: This is an Open Access article distributed in accordance with the Creative Commons Attribution-NonCommercial-NoDerivs 4.0 International License (CC BY-NC-ND 4.0), which permits the non- commercial replication and distribution of the article with the strict proviso that no changes or edits are made and the original work is properly cited (including links to both the formal publication through the relevant DOI and the license). See: https://creativecommons.org/licenses/by-nc-nd/4.0/.

\section{References}

1. Coppo R. Pediatric IgA nephropathy: clinical and therapeutic perspectives. Semin Nephrol 2008;28:18-26.

2. Tomino Y, Suzuki S, Imai H, et al. Measurement of serum IgA and C3 may predict the diagnosis of patients with IgA nephropathy prior to renal biopsy. J Clin Lab Anal 2000;14:220-3.

3. Komatsu H, Fujimoto S, Hara S, et al. Relationship between serum IgA/C3 ratio and progression of IgA nephropathy. Intern Med 2004;43:1023-8.

4. Tomino Y. Relationship between the serum IgA/C3 ratio and the progression of IgA nephropathy. Intern Med 2004;43:1011.

5. Yanagawa H, Suzuki H, Suzuki Y, et al. A panel of serum biomarkers differentiates IgA nephropathy from other renal diseases. PLoS One 2014;9:e98081.

6. Mestecky J, Novak J, Moldoveanu Z, et al. IgA nephropathy enigma. Clin Immunol 2016;172:72-7.

7. Kawasaki Y, Maeda R, Ohara S, et al. Serum IgA/ $\mathrm{C} 3$ and glomerular C3 staining predict severity of IgA nephropathy. Pediatr Int 2018;60:162-7.

8. Coppo R. Clinical and histological risk factors for progression of IgA nephropathy: an update in children, young and adult patients. J Nephrol 2017;30:339-46.

9. Coppo R, Robert T. IgA nephropathy in children and in adults: two separate entities or the same disease? J Nephrol 2020;33:1219-29.

10. Suzuki H, Kiryluk K, Novak J, et al. The pathophysiology of IgA nephropathy. J Am Soc Nephrol 2011;22:1795-803.

11. Wu MY, Chen CS, Yiang GT, et al. The Emerging Role of Pathogenesis of IgA Nephropathy. J Clin Med 2018;7:225.

12. Maillard N, Wyatt RJ, Julian BA, et al. Current Understanding of the Role of Complement in IgA Nephropathy. J Am Soc Nephrol 2015;26:1503-12.

13. Wyatt RJ. The complement system in IgA nephropathy and Henoch-Schonlein purpura: functional and genetic aspects. Contrib Nephrol. 1993;104:82-91.

14. Yoshikawa N, Tanaka R, Iijima K. Pathophysiology and treatment of IgA nephropathy in children. Pediatr 
Nephrol 2001;16:446-57.

15. Mizerska-Wasiak M, Maldyk J, Rybi-Szuminska A, et al. Relationship between serum IgA/C3 ratio and severity of histological lesions using the Oxford classification in children with IgA nephropathy. Pediatr Nephrol 2015;30:1113-20.

16. Huang YJ, Liang MJ, Zhou JF, et al. Elevated baseline serum IgA may predict earlier proteinuria remission in IgA nephropathy patients. Int J Clin Exp Pathol 2017;10:10475-82.

17. Ştefan G, Ismail G, Stancu S, et al. Validation study of Oxford Classification of IgA Nephropathy: the significance of extracapillary hypercellularity and mesangial IgG immunostaining. Pathol Int 2016;66:453-9.

18. Mizerska-Wasiak M, Maldyk J, Turczyn A, et al. Predictors of Progression in IgA Nephropathy in Childhood. Adv Exp Med Biol 2017;955:65-73.

19. Kim SJ, Koo HM, Lim BJ, et al. Decreased circulating C3 levels and mesangial C3 deposition predict renal

Cite this article as: Lang Y, Song S, Zhao L, Yang Y, Liu T, Shen Y, Wang W. Serum IgA/C3 ratio and glomerular C3 staining predict progression of IgA nephropathy in children. Transl Pediatr 2021;10(3):666-672. doi: 10.21037/tp-21-90 outcome in patients with IgA nephropathy. PLoS One 2012;7:e40495.

20. Medjeral-Thomas NR, Lomax-Browne HJ, Beckwith H, et al. Circulating complement factor H-related proteins 1 and 5 correlate with disease activity in IgA nephropathy. Kidney Int 2017;92:942-52.

21. Nakagawa H, Suzuki S, Haneda M, et al. Significance of glomerular deposition of C3c and C3d in IgA nephropathy. Am J Nephrol 2000;20:122-8.

22. Jullien $P$, Laurent B, Claisse $G$, et al. Deletion Variants of CFHR1 and CFHR3 Associate with Mesangial Immune Deposits but Not with Progression of IgA Nephropathy. J Am Soc Nephrol 2018;29:661-9.

23. Stefan G, Stancu S, Boitan B, et al. Is There a Role for IgA/C3 Ratio in IgA Nephropathy Prognosis? An Outcome Analysis on An European Population. Iran J Kidney Dis 2020;14:470-7.

(English Language Editor: J. Jones) 